\title{
Breast Cancer Cutaneous Metastasis after Scalp Cooling for Alopecia Prevention
}

\author{
Elimar Elias Gomes ${ }^{*}$, Maria C. C. Ferreira',2, Amanda B. Karani1, Marcelo Sato-Sano1, \\ Mariana N. Meireles ${ }^{1,2}$, Carlos E. Bacchi³, Mariana Dias Batista ${ }^{1,2}$, Fernando C. Maluf ${ }^{1}$ \\ ${ }^{1}$ Oncology Center, Beneficencia Portuguesa de Sao Paulo, Sao Paulo, Brazil \\ ${ }^{2}$ Department of Dermatology, Federal University of Sao Paulo, Sao Paulo, Brazil \\ ${ }^{3}$ Laboratorio Bacchi, Botucatu, Brazil \\ Email: ^elimargomes@me.com
}

How to cite this paper: Gomes, E.E., Ferreira, M.C.C., Karani, A.B., Sato-Sano, M., Meireles, M.N., Bacchi, C.E., Batista, M.D. and Maluf, F.C. (2020) Breast Cancer Cutaneous Metastasis after Scalp Cooling for Alopecia Prevention. Journal of Cancer Therapy, 11, 745-748.

https://doi.org/10.4236/jct.2020.1111064

Received: August 22, 2020

Accepted: November 23, 2020

Published: November 26, 2020

Copyright (c) 2020 by author(s) and Scientific Research Publishing Inc. This work is licensed under the Creative Commons Attribution International License (CC BY 4.0).

http://creativecommons.org/licenses/by/4.0/

\begin{abstract}
Scalp cooling is a widely used method to prevent chemotherapy-induced transient alopecia. Although the success rates in maintaining hair can be high, authors have expressed their concerns regarding the risk of scalp metastasis after scalp cooling. We report a case of breast cancer scalp metastasis in a patient submitted to scalp cooling for alopecia prevention and discuss the physiopathology, risks and benefits of this treatment for patients under this treatment.
\end{abstract}

\section{Keywords}

Skin Metastasis, Scalp Cooling, Chemotherapy-Induced Alopecia

\section{Introduction}

Chemotherapy-induced alopecia (CIA) is a psychologically distressing consequence of some cancer treatments, especially for women. CIA usually is reversible, [1] and varies according to the chemotherapy regimen, doses and duration of treatment [2]. Scalp cooling is the most widely used and studied method to prevent alopecia. Some authors have expressed their concerns about the risk of scalp skin metastasis after scalp hypothermia. This is because the procedure minimizes delivery of chemotherapeutic agents to the scalp thus it could leave a "sanctuary" of untreated cancer cells. This subject which has been studied recently has been a reason for discussion whether there is a real increased risk of scalp metastasis [2].

Cutaneous metastases are relatively rare in clinical practice, occurring in $0.7 \%$ - 9.0\% of patients with internal neoplasms depending on the series [3]. Breast 
cancer is among the neoplasms that show a great tendency to spread to the skin. The most common sites of cutaneous metastasis of breast cancer are the chest wall and abdomen, but they can also occur on extremities and head/neck region [4].

We present a case of breast cancer scalp metastasis in a patient who was submitted to scalp cooling.

\section{Case Report}

A 75-year-old woman was diagnosed with breast cancer in 2002. She was submitted to bilateral mastectomy, axillary dissection, radiation therapy and chemotherapy. Her systemic treatment was 6 CFM cycles (cyclophosphamide, 5-fluorouracil and mitoxantrone). Scalp cooling was not used during this first treatment. The patient maintained complete response for 5 years, until a recurrence occurred as a pleural effusion. She was submitted to thoracoscopy and pleurodesis and pathology showed pleural metastatic breast carcinoma, HER2-negative, estrogen receptor-positive and progesterone receptor-positive. She received 9 cycles of docetaxel, trastuzumab and pertuzumab and was submitted to scalp cooling since the first cycle for all 9 cycles during therapy infusion. Four months after the end of chemotherapy, she noticed asymptomatic nodules on her scalp. Clinical examination revealed multiple hardened erythematous skin nodules on the occipital portion of the scalp (Figure 1(A)). Dermoscopic examination demonstrated linear irregular and thin arborizing vessels (Figure 1(B)). Biopsy was performed and the histopathological analysis resulted in metastatic carcinoma compatible with lobular breast carcinoma cutaneous metastasis (Figure 2). There was a switch of the systemic treatment to cisplatin and gemcitabine and scalp cooling was interrupted.

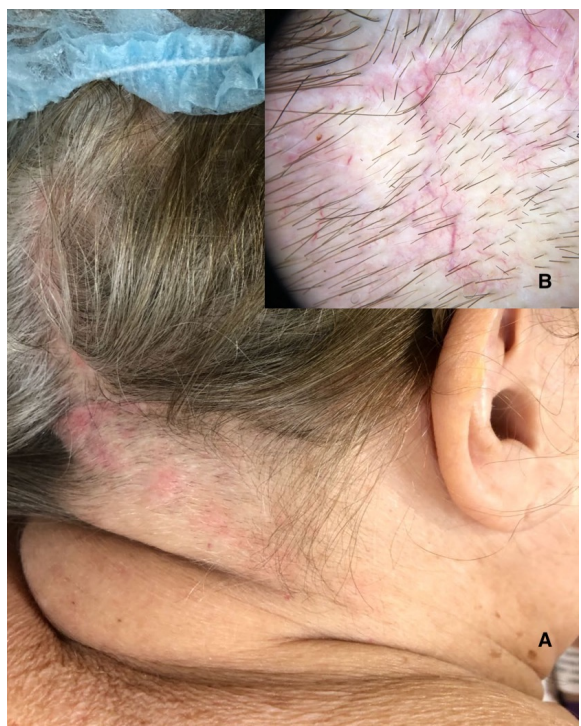

Figure 1. (A) Posterior aspect of the scalp (occipital area) presenting nodules of 4 to 8 $\mathrm{mm}$ with a slightly erythematous surface, distributed throughout the scalp, mainly at the occipital region. (B) Dermoscopy showing Linear irregular and thin arborizing vessels on dermoscopy. 


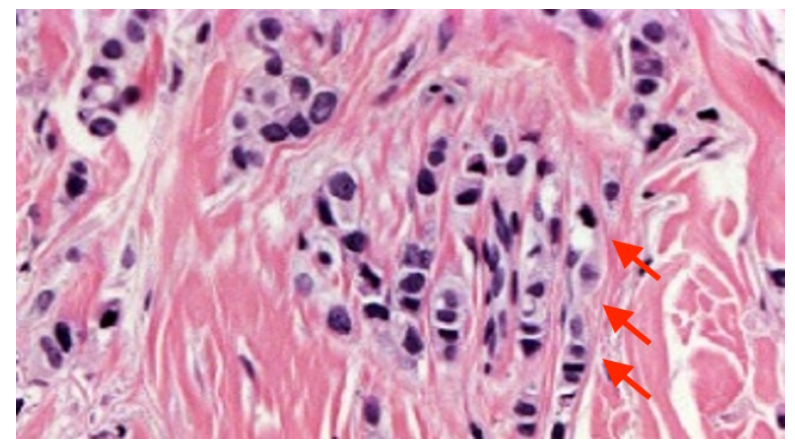

Figure 2. Skin biopsy (HE-40x) showing dermal neoplasm with rounded cells forming vertical cords (arrows).

\section{Discussion}

Chemotherapy-induced alopecia (CIA) is an acquired form of hair loss and one of the most devastating consequences of breast cancer treatment, especially for women [5]. Most cases of CIA begin two to four weeks following initiation of chemotherapy and resolves within three to six months of drug cessation [6]. Scalp cooling has been used in several countries to prevent transient alopecia during the treatment. In theory, cooling causes vasoconstriction on the scalp, reducing blood flow to hair follicles and possibly decreasing biochemical activity, making hair follicles less susceptible to chemotherapy damage [7]. As the process of cooling reduces drug levels on the scalp, an increased risk of scalp metastasis is a reason of concern [2].

Skin metastases of breast cancer appear to occur following the diagnosis of generalized metastatic disease [8]. A wide spectrum of clinical presentations has been described, including nodules, papules, plaques, tumors, and ulcers [2]. Most lesions appear as a discrete firm painless nodule [3].

A recent literature review on scalp metastases following adjuvant chemotherapy for early-stage breast cancer considered unlikely that the incidence of scalp metastasis might increase after scalp cooling [9]. A systematic review and meta-analysis evaluated patients with breast cancer that received chemotherapy while using scalp cooling and also did not support the concern for scalp metastatis in patients submitted to scalp cooling during chemotherapy [7]. Therefore, it's unlikely that scalp cooling increases the incidence of scalp metastasis in patients with early-stage breast cancer receiving chemotherapy.

In our reported case, scalp metastases after scalp cooling were not the first metastatic site, they accompanied widespread metastatic disease.

Breast cancer scalp metastases are rare entities that can arise with or without scalp cooling. Evidence based on literature review demonstrates that it is unlikely that scalp cooling increases the incidence of scalp metastases. However, further studies should provide conclusions regarding clinical outcomes and safety.

\section{Conflicts of Interest}

The authors declare no conflicts of interest regarding the publication of this paper. 


\section{References}

[1] Trüeb, R.M. (2009) Chemotherapy-Induced Alopecia. Seminars in Cutaneous Medicine and Surgery, 28, 11-14. https://doi.org/10.1016/j.sder.2008.12.001

[2] Lemieux, J., Desbiens, C. and Hogue, J.C. (2011) Breast Cancer Scalp Metastasis as First Metastatic Site after Scalp Cooling: Two Cases of Occurrence after 7- and 9-Year Follow-Up. Breast Cancer Research and Treatment, 128, 563-566. https://doi.org/10.1007/s10549-011-1453-y

[3] Rodríguez-Martín, A.M., Ruano-Ruiz, J. and Vélez-García-Nieto, A. (2016) Cutaneous Metastases: Clinical and Dermatoscopically Simulating Multiple Dermatofibromas. International Journal of Dermatology, 55, 574-576. https://doi.org/10.1111/ijd.12895

[4] Alcaraz, I., Cerroni, L., Rütten, A., et al. (2012) Cutaneous Metastases from Internal Malignancies: A Clinicopathologic and Immunohistochemical Review. The American Journal of Dermatopathology, 34, 347-393. https://doi.org/10.1097/DAD.0b013e31823069cf

[5] Nangia, J., Wang, T., Osborne, C., Nivarath, P., Otte, K., Papish, S., et al. (2017) Effect of a Scalp Cooling Device on Alopecia in Women Undergoing Chemotherapy for Breast Cancer: The SCALP Randomized Clinical Trial. JAMA, 317, 596-605. https://doi.org/10.1001/jama.2016.20939

[6] Shah, V.V., Wikramanayake, T.C., DelCanto, G.M., van der Hurk, C., Wu, S., Lacouture, M., et al. (2018) Scalp Hypothermia as a Preventative Measure for Chemotherapy-Induced Alopecia: A Review of Controlled Clinical Trials. Journal of the European Academy of Dermatology and Venereology, 32, 720-734.

https://doi.org/10.1111/jdv.14612

[7] Rugo, H.S., Melin, S.A. and Voigt, J. (2017) Scalp Cooling with Adjuvant/Neoadjuvant Chemotherapy for Breast Cancer and the Risk of Scalp Metastases: Systematic Review and Meta-Analysis. Breast Cancer Research and Treatment, 163, 199-205. https://doi.org/10.1007/s10549-017-4185-9

[8] Krathen, R.A., Orengo, I.F. and Rosen, T. (2003) Cutaneous Metastasis: A MetaAnalysis of Data. Southern Medical Journal, 96, 164-167.

[9] van den Hurk, C.J., van de Poll-Franse, L.V., Breed, W.P., Corbergh, J.W.W. and Nortier, J.W.R. (2013) Scalp Cooling to Prevent Alopecia after Chemotherapy Can Be Considered Safe in Patients with Breast Cancer. Breast, 22, 1001-1004. https://doi.org/10.1016/j.breast.2013.07.039 